\title{
THE STRUGGLES AND THE TRIUMPHS OF SOUTH AFRICAN BLACK WOMEN PROFESSORS
}

\author{
N. T. Zulu \\ Department of Psychology \\ University of KwaZulu-Natal \\ Durban, South Africa
}

\section{ABSTRACT}

The apartheid epoch introduced a web of laws that influenced public and private structures and ideological apparatuses, including educational institutions, to give an inferior status to Black people. South Africa was also upheld by a deeply patriarchal system which marginalised the status of women in society. This meant that most people in senior positions in South African organisations were predominantly white and male. The consequence of racism and patriarchy meant that there have been a low number of Black women professors in institutions of higher education. This study therefore aimed to examine the discourses of Black women professors in post-apartheid South Africa. This study used the Critical Race Theory (CRT) and critical consciousness, to understand the challenges that Black women professors encounter and how they strategically navigated these challenges in institutions of higher education, respectively. The Black women professors were recruited from two South African universities. Semi-structured interviews were used to collect the data. The data was analysed using thematic analysis. The significance of the study is that it identified discourses, which could be useful to understand the kinds of challenges that may operate in higher education and ways to shift these existing challenges. The findings showed two main challenges encountered by Black women professors namely: (1) feelings of being unwelcomed within the academic space and (2) being undermined in their leadership positions. Black women professors seemed to navigate these challenges by (1) being vocal, and (2) being intentional, about excelling in their work and (3) adopting a transformational leadership style. The study feeds into how South African higher education institutions can accommodate Black women professors, as they navigate through their career.

Keywords: Black women professors, academics, higher education institutions, challenges, critical race theory, critical consciousness.

\section{INTRODUCTION}

There is much literature that explicates how Black women academics in South African higher education institutions are not exempt from the issues of racism and sexism that plague Black women in other domains of professional and social life (Divala 2014; Khunou et al. 2019; Mokhele 2013; Naicker 2013; Schulze 2015). The racism and sexism can bring about obstacles that prevent Black women's attainment of professorship which is one of the reasons for the 
scarcity of Black women professors within the South African landscape. Literature shows that Black women academics encounter a number of challenges and obstacles within the university that lead some of them to quit in the early stages of their academic careers, before reaching professorial level (Mandleco 2010). Other Black women academics never reach the professoriate, even if they do continue their careers in institutions of higher education (Mandleco 2010). Statistics South Africa (Stats SA 2016) indicated that there are more females (51\%) than males (49\%) in South Africa, however men continue to dominate in the higherranking academic positions (DHET 2018). Moreover, most of the professors and others in senior ranks are White (DHET 2018), even though the Black African population is and was in the majority in South Africa (Stats SA 2016).

While there is South African literature on Black women academics within the higher education setting, there is not much that focuses on Black women professors (and their challenges and triumphs). The small number of Black women making it to professorship is likely to have implications for younger Black women academics who aspire to reach professorship levels. If younger Black women academics do not encounter professors who they personally identify with (in terms of race and gender), they may not be enthused to pursue professorship. The understanding of the challenges that Black women professors encounter and their triumphs is needed in order to disseminate what younger Black and women academics can expect when going into higher education institutions with the hopes of attaining professorship. This would be beneficial as it could assist more Black women academics in becoming professors. Presenting the challenges that Black women professors encounter can assist higher education institutions to come up with strategies that might lessen these challenges so that more Black women professors can thrive. Presenting the triumphs of Black women professors can also assist higher education institutions in informing the interventions and programmes that they come up with to overcome the challenges so that more Black women academics can stay and even succeed to professorship. This article therefore seeks to uncover the ways in which Black women professors construct professorship, in relation to their experiences in postapartheid South Africa. More specifically, the article seeks to explore (1) what the challenges that Black women professors encounter are and (2) how Black women professors strategically navigate these challenges in higher education institutions.

\section{BEING A BLACK WOMEN ACADEMIC IN SOUTH AFRICA}

Inasmuch as Black women professors can contribute to institutions of higher education, they are often met with discrimination. Research has revealed disturbing implications of racism within institutions of higher education and the endemic structures that marginalised Black 
women and men (Mzangwa 2018; Naicker 2013). Women have also been victims of sexism in the patriarchal higher education institutions.

The sole purpose of patriarchy was to ensure male dominance and female submission (Dlamini and Adams 2014), which emphasised gender inequality, in institutions of higher education. Black women are therefore often victims of both sexist and racist subjugation, which establishes a unique double intersectional burden for them. Despite the introduction of inclusive policies that enable accessibility to higher education among students and staff from different races and backgrounds, the legacy of the apartheid system persists even decades later (Mohope 2014; Mzangwa 2018). Both Black students and staff still experience discrimination within these spaces (Mohope 2014), which for Black women academics usually results in their demoralisation in the higher education community (Collins 2001; Zulu 2013; Maphalala and Mpofu 2017).

The literature suggests that many Black academics located in White universities do not feel free to be themselves among students and colleagues (Allison 2008; Mohope 2014). Black academics are often in the minority, marginalised and isolated; and therefore, their voices are often silenced (Ramohai and Marumo 2016; Dlamini and Adams 2014). Encounters such as having their intelligence, qualifications, and authority constantly called into question, being excluded from important activities, and having White people judge them, according to negative stereotypes, are some of the difficulties that Black women encounter in higher education (Ndlovu 2014; Msimanga 2014; Mokhele 2013).

South African literature also shows that Black women academics repeatedly have difficulty gaining promotion, they receive less pay, and they are forced to carry out research and teaching activities in hostile environments (Subbaye and Vithal 2017). Another obstacle that some Black (women) academics have had to endure is the possibility that they were token placements used by former White higher education institutions as evidence that institutional affirmative action programme requirements were met (Schulze 2015; Maodzwa-Taruvinga and Msimanga 2014). Most Black (women) academics have often been treated with a lack of respect and given few opportunities to be part of communities that could support them to develop identities as productive academic members (Vandeyar 2010). Women are therefore not expected to be high-powered academics, especially in hard science fields (Dlamini and Adams 2014), and therefore those who do triumph can sometimes encounter harassment, as some of their male leaders can find them threatening. Some of the more successful women in higher education institutions encounter persistent mistreatment, and they are sometimes forced to resign or endure a hostile environment. Nevertheless, there are some Black women who succeed in overcoming these difficulties and end up attaining a professoriate title in higher education 
institutions.

A study conducted by Schulze (2015) identified supportive strategies that women academics can utilise as they navigate higher education institutions. Factors such as supportive opportunities from their organisation, supervisors and mentors emerged as areas to consider in supporting the professional identity of Black women academics. This implies that there are some tangible approaches that can be applied to combat systematic oppression and barriers that might hinder Black women from doing well in higher education institutions.

Having an accommodating and supportive dean or department chair has been asserted to assist the Black women academics in making a success of their careers (Schulze 2015). An academic leader that is assertive about inclusivity encourages formal mentoring within the discipline, monitoring for equity in workload, explicit in communicating performance expectations and advice on developmental evaluations and providing clear guidelines for promotions (Mokhele 2013; Schulze 2015). The involvement of Black women academics with each other's professional identity and being able to connect and reach out to one another is also deemed as an important source of support (Ramohai 2019). Being a member of Black professional associations, networking in professional conferences, being active participants in social media platforms that are dedicated to motivate young academics to pursue the academy are all considered essential to the success of Black women academics (Mokhele 2013; Schulze 2015). Of particular importance, mentors can assist Black women in their resistance to institutional and organizational barriers by illuminating opportunities that may assist them in succeeding in higher education. The implication of not receiving support as a Black woman academic can be isolating and difficult as they navigate their disciplines, departments, and institutions. When Black women are not connected to networks in their disciplines, departments, and or institutions and can find themselves situated as the only Black woman in their program, department, or college and feelings of isolation and marginalization may be inevitable. Feelings of exclusion can then affect the number of Black women academics that make it to professorship.

\section{PROFESSORSHIP IN HIGHER EDUCATION}

Professors achieve their position by displaying continuous excellence in an academic discipline over many years (McCracken-Flesher 2010). Professors within higher education institutions serve a combination of two overarching purposes. Firstly, they enhance and boost institutions' statuses and profiles (Evans 2015), and secondly, they provide academic leadership. Professors are also significant in that they have the responsibility of shaping and developing the next generation of academics, through career development, mentoring and advising. The implication 
of this interpretation is that professorship is essential in higher education institutions and therefore presenting the challenges that Black women professors encounter is crucial in understanding why some Black women academics do not make it to professorship. In addition, the challenges presented can assist in explaining the scarcity of Black women professors.

Of concern is the overall shrinking numbers in the professoriate (in the ranks of both full professor and associate professor) in South Africa (Subbaye 2017). This could yield undesirable repercussions for South African knowledge production and academic leadership, over time. The implication is that more professors are needed and therefore information about the way that Black women professors triumph over the challenges that they encounter is vital as it can assist higher education institutions in initiating strategies that might reduce challenges encountered by Black women academics in making it to professorship. Moreover, this information might assist more Black women professors in countering their challenges and triumphing over them and therefore be in a better position to contribute in the knowledge production and academic leadership.

Discourses on how some of the successful Black women professors made meaning of their higher education challenging experiences, and how they constructed themselves to counter these struggles are needed; as white and male supremacy in the academic space has been deliberately institutionalised to continuously entrench discrimination (Miroiu 2003).

The critical race theory (CRT), combined with critical consciousness, will be used to understand the struggles and the triumphs of Black women professors within the South African context. CRT critically confronts the laws that uphold White supremacy within a culture. CRT will give the lens to understanding the struggles that Black women professors encounter within higher education institutions. Increased critical consciousness results in an individual's recognition of the power dynamics at work in predominately White spaces. Critical consciousness also leads to a need for increased strength and resilience to assist with being able to negotiate such contexts and hence for this study it will give the lens to understanding how Black women professors triumph over challenges in higher education institutions. This framework will be presented next.

\section{CRITICAL RACE THEORY}

Due to the racism and patriarchy that exists in higher education institutions, Black women have been one of the most isolated, underused and consequently demoralised personnel in the higher education community (Rollock 2019; Zulu 2013; Collins 2001). Despite the introduction of inclusive policies that enable higher education to be accessible to students and to staff from different races and backgrounds, the legacy of the discriminatory system is still persistent, even 
decades later (Albertus 2019; Mohope 2014; Bezuidenhout and Cilliers 2011). It is for such reasons that a group of Black American scholars realised a need for alternative and more critical descriptions for the existence of racism, which resulted in the emergence of the Critical Race Theory (CRT) (Aguirre 2000; Taylor 1998). CRT aimed to critically challenge the laws that maintained white supremacy, that were entrenched within the United States of America's governmental and legal structures and a culture that was almost unrecognisable (Delgado and Stefancic 2000).

CRT has five tenets that can be used to analyse the different forms of social inequities, which can be reinforced through institutions of higher education. These are: the permanence of racism, whiteness as property, interest conversion, critiques of liberalism and counterstorytelling. These tenets address different, yet interconnected themes, and they help unearth the various ways in which institutions reinforce racism (Hiraldo 2010).

Under the permanence of racism, this theory postulates that racism is seen as an inherent part of society, privileging White individuals over Black people, in most areas of life, including education (Hiraldo 2010). Whiteness as property asserts that the set of assumptions and benefits that accompany the status of being White has become a valuable asset, which White people sought to protect (Harris 1993). For this study, this tenet assists in understanding that Black South African academic professionals might enjoy less privilege of being affirmed, legitimated or protected by the laws that govern the higher education system, due to not being White. The interest of conversion tenet asserts that the interests of Black people achieving racial equality have been accommodated only when they have converged with the interests of powerful whites. This tenet could explain the limited number of Black academic leaders in South African higher education, as a result of powerful White academics feeling that their privilege would be threatened should a large number of Black people be part of management. The critique of liberalism tenet emerges from the idea that the main legal claims of neutrality and colourblindness are camouflaged for the self-interests of powerful entities in society (Tate 1997; Taylor, Gillborn, and Ladson-Billings 2009). It is stated that liberalism in this case is deemed patronising, as it works in higher education institutions to maintain the status quo. Critiquing of the liberal perspective in higher education has, perhaps not been at the forefront of South African higher education and therefore the experiences of Black women academics, dealing with racism, have not been challenged but rather perpetuated. Lastly, in counter-storytelling, CRT values stories of "raced" people whose experiences are often not told; stories that expose, analyse, and challenge the majoritarian stories of racial privilege (Stinson 2013; Aguirre 2000). The CRT is a framework that legitimises the racial and the subordinate experiences of marginalised groups (Hiraldo 2010). 
This theory was appropriate for this study as it extracts what is taken for granted when analysing race and privilege, as well as examining profound patterns of marginalisation that exist in the social order. Therefore, CRT plays an important role for higher education institutions who are striving for transformation, through becoming more diverse and inclusive (Hiraldo 2010). CRT shifts the research lens away from a deficit view of Black communities being regarded as places full of cultural poverty or disadvantages, and instead focuses on and learns from these communities' cultural assets and wealth (Yosso 2005) through the counterstorytelling.

\section{CRITICAL CONSCIOUSNESS}

Critical consciousness originated from the works of Paulo Freire (1972). He outlined critical consciousness as involving both reflection and action that focused on systematic societal changes (Freire 1972). Critical consciousness is useful for understanding how Black women professors succeeded in a challenging academic environment. This theory and concept relate to efforts that overpower suppression and promote human progress and advancement, community involvement, and welfare (Christens, Lawrence, and Adrienne 2015). Critical consciousness offers a broader relative prominence on the cognitive features of civic development, as being distinct from empowerment's emphasis on emotional features.

While working together with unschooled and impoverished Brazilians, Freire (1972) inspired them to think about political and social injustices in a critical way. He believed that a rational and informed understanding of history, economics, poverty, oppression and exploitation was a prerequisite for underprivileged individuals to initiate and to establish a progressive change. Consciousness of social and economic inequities and their causes places marginalised individuals in a position to resist oppressive systems effectively and insists on transforming their social and their political circumstances (Freire 1972). Supported by Freire's (1972) work, researchers have built critical consciousness as an assessment of oppression and as a recognition of societal injustices (Magee and Phelari 2019). Oppression is perceived as a practice that supports the disproportionate allocation of essential resources and impacts the quality of life of the poor and the marginalised populations in an adverse manner (Christens et al. 2015). As stated earlier, Black women professors have encountered oppression in the academic space, and this theory helps in understanding how they resisted the unjust systems and promoted transformation within their institutions of higher education.

Critical consciousness leans towards the freeing from numerous forms of suppression. In the USA, scholarships on critical consciousness is centred on endeavours to resolve racial oppression and activities, and to challenge supplementary systems of identity-based oppression. 
Critical consciousness and the related notion of socio-political development are focused on social change and social justice (Watts and Serrano-García 2003). In South Africa, most studies that examine critical consciousness have a focus on transformation and social justice in education, teaching, learning and disease prevention among young people (Maseko 2018; Hatcher 2006; Campbell and MacPhail 2002).

From critical consciousness it could be suggested that some Black women academics were able to do well in higher education, due to being critically aware of the oppression and the exploitation of their race and gender, and were therefore intentional in resisting oppressive systems and being assertive on changing their social and their political circumstances. Dialogues about political issues with parents, teachers and peers could have played a role in the consciousness of Black women academics who eventually become professors. Through career aspirations and interests, Black women professors should have been more devoted to their future careers thereby confirming that their work headed toward accomplishing their goals.

Scholars have identified three core components of critical consciousness: critical reflection, critical efficacy, and critical action. Critical reflection is the process of learning to question social arrangements and structures that marginalize groups of people. This includes history and thinking that perpetuates existing structures of inequalities. Critical efficacy refers to the perceived capacity and the commitment to address perceived injustices. Critical action is the individual or the collective engagements and the efforts to change perceived injustices. As individuals continue through these phases, they are gradually equipped to link their personal encounters to community matters and to come up with better judgements on promoting change (Christens et al. 2015). Critical action is orientated towards the understanding that the actions it incorporates are those exclusively leaning toward removing unjust systems and policies (Christens et al. 2015).

\section{METHOD}

\section{Participants}

A qualitative design was employed to find out the meaning that Black women professors derive from their professorship and how they portray themselves in South African institutions of higher education. A blend of purposive and snowballing sampling strategies was used as a participant recruiting style (Merriam 2009). The purposive sampling strategy was chosen, as it offered an intentional selection of information-rich participants, who the researcher was able to study in an in-depth manner (Galbin 2014).

The interviews were conducted with eight Black women professors (associate and full) 
from two South African universities. The participants were from various faculties including humanities, health sciences, law and management studies, agriculture, engineering and science. Interviews were conducted in English and in IsiZulu.

\section{Interview schedule}

The researcher conducted one-on-one semi-structured interviews with the participants. Semistructured interviews were appropriate for this study, as they allowed reflection and in-depth discussions to be achieved, through probing the participants for the expansion of their responses, while keeping some structure in the interview (DeJonckheere and Vaughn 2019). The semi-structured interview schedule allowed the researcher to follow the direction that the participants took in the interview, while concurrently probing them within the parameters of the topic of interest (McGrath, Palmgren, and Liljedahl, 2019).

\section{Procedure}

Ethical clearance for this study was granted by the University of KwaZulu-Natal Human and Social Sciences Research Ethics Committee (Protocol reference number: HSS/2053/017M). Once ethical clearance was granted, the researcher sent out e-mails to potential participants, detailing the information of the study. The interested and the available participants responded positively to the e-mail. The snowballing sampling technique was also used to recruit other participants. The interested participants and the researcher agreed on an appropriate time and venue for the interview.

Before the commencement of the interviews, the participants were told about their rights as participants of the study, and they were asked to sign an informed consent form, signalling their volunteerism to participate and to being audio recorded. Interviews were thereafter conducted with the participants. The semi-structured interviews took between 45 and 90 minutes. After the interviews were conducted, the researcher immersed herself in the audiorecorded data, transcribed the interviews and commenced with the data analysis.

\section{DATA ANALYSIS}

A thematic analysis approach was adopted for this study. According to Braun and Clarke (2006; 2012) a theme encapsulates something important about the data, in relation to the research question and it represents some level of patterned response or meaning within the data set. The thematic data analysis was appropriate for this study, as it describes the data in detail, by identifying, analysing and reporting on patterns or themes within the data. Due to its flexibility (as it can be used across a range of data types), this analysis allowed issues relating to race, 
gender and power relations to be identified.

The study followed six main steps in doing thematic data analysis, in order to answer the research question. Firstly, the researcher familiarized herself with the data and identified items of interest. Secondly, the researcher generated the initial codes which identified features of the data which were interesting. Thirdly, the researcher looked for the themes which were coherent and had meaningful patterns in the data, relevant to the research question.

In doing this, the coded data was reviewed to assist in identifying potential themes. After step three was done, the nature or the character of the potential themes was identified. Here, the researcher considered the quality of the themes and the amount of meaningful data to support each theme. The fifth stage involved the researcher defining and naming each of the themes. Here, the specifics of each theme and the overall story of the analysis was refined. The final step was deciding on the order in which to present the themes, selecting compelling and rich examples of data, to illustrate each theme (Braun and Clarke 2012).

\section{RESULTS AND DISCUSSIONS}

The extracts below illustrate how the participants (using pseudonyms) experienced the challenges that they encountered and how they strategically navigated these challenges in institutions of higher education.

\section{Challenges for Black women professors in institutions of higher education}

\section{Being unwelcome as professors within the academic space}

The literature shows that Black women have been one of the most isolated and consequently demoralised personnel of the higher education community (Rollock 2019; Zulu 2013; Collins 2001). Despite the introduction of inclusive policies that enable higher education to be accessible to members of all races and gender groups, the legacy of the discriminatory system is still persistent, even decades later (Albertus 2019; Mohope 2014; Bezuidenhout and Cilliers 2011). The discrimination and the disregard that Black women professors encountered is illustrated in this study, as the participants discredited some White and male academics and portrayed them as perpetrators that were active in their disempowerment as academics.

When discussing her experience about being promoted to professorship, Hlengiwe stated that:

“They said no, your professor removed this and they said you can't get professorship ... and I went to him and said why? And he said you are young ... I qualified according to the university criteria for professorship, but he never gave it to me. Black male, he never gave it to me. And uh ... funny 
enough and there were white head of departments who were employed after me, they were given

... but I have been having those challenges in senior management where I'm the only female."

Zinhle mentioned that:

"Still, as a Black person you will still be overlooked, as you walk into a room a lot of [White] people are seeing you as a Black person, more than seeing you as an equal."

Hlengiwe's extract is in line with Dlamini and Adams (2014) and Zulu (2013), who argued that women are expected to occupy low-status jobs in higher education institutions. Hlengiwe even in the advanced stages of her academic career positioned herself as a victim of discrimination, whereby she was hindered from getting her deserved professorship title, due to not being the required age, race and gender that was preferred by her superiors. She in turn, was portraying her Black male senior as a suppressor who was hindering her from attaining influence as part of a managerial position. This may be because women are not expected to be high-powered academics, especially in the hard science fields (Dlamini and Adams 2014), and those who do triumph can sometimes encounter harassment, as their insecure male leaders find them threatening. Hindering women from getting promoted to higher academic levels probably leads them to have the least power and authority in academic decision-making (Subbaye and Vithal 2017), which then leads to inequalities associated with power and authority, which can further shape the experiences of Black women in South African higher education institutions.

Zinhle showed how her fellow White academics had acknowledged her more for her race, rather than for her academic credentials. This is in line with CRT's Whiteness as property which asserts that the set of assumptions and benefits that accompany the status of being White has become a valuable asset which White people sought to protect (Harris 1993). For this study, this tenet assists with understanding that Black South African academic professionals might enjoy less privileges of being affirmed, legitimated or protected by the laws that govern the higher education system, due to not being White. The interest of conversion asserted that the interests of Black people achieving racial equality were only accommodated when they coincided with the interests of powerful whites. This tenet could explain the limited number of Black academic leaders in South African higher education, as a result of powerful White academics feeling that their privileged positions would be threatened should a large number of Black people become part of management.

\section{Being undermined in their leadership position}

Most of the participants discredited some of their White, Indian and male colleagues and portrayed them as oppressive and as undermining their leadership as professors. The 
participants' authority as professors was undermined by their colleagues and those under them due to their race, gender and sometimes age. While talking about her work experience Thobile stated that:

"So, when you come across a Black woman leading in the workplace it doesn't seem right to them ... an example, there were those who were refusing that I be their leader because they were White. They straight up refused that I lead them because they were White in such a way, that in cases where I have to sign for them where I am supposed to sign as the leader, the person would go and sign for themselves and say they are the leader."

While talking about her experience as a professor, Sbahle indicated the following:

"[white males] they overlook you. You know what there is still this uh ... male domination environment where the school committee they just choose themselves and they will be in charge of everything and they forget that you are there. Yes, and it doesn't help that I'm younger, so I mean ... it combines."

Thobile also stated:

"Black men also oppress us in addition to us being oppressed by other races. The Black men oppress us because they have the belief that they will not be led by a Black woman. It is something that is happening, and it won't stop. Even me being here, they are here, and they don't want me to lead them because they are men, who is a woman that she would lead a man?"

In the above quote, Thobile indicated how some White colleagues who were under her undermined her authority as their leader and refused to submit to her. Both Sbahle and Thobile also indicated how sexism by both Black and White males also played a role in how they were undermined as professors in higher education. Sbahle spoke about how she and her contributions in the school committee were ignored and disregarded. Male power and other institutional barriers can suppress the voices of the women; thus, preventing them from leading effectively and becoming change agents within their institutions (Ramohai and Marumo 2016).

The participant's experience is in line with the permanence of racism and Whiteness as property tenets of CRT, which argue that racism is seen as an inherent part of society, privileging White individuals over Black people, even in higher education. It is suggested that the same principle can be applied to how patriarchy can also be seen as an innate part of society, benefiting men over women in higher education. Black South African professors in this study (as the literature suggests) therefore enjoy less privilege of being affirmed, legitimated or protected by the laws that govern the higher education system, due to not being White (Hiraldo 2010). Here the participants positioned their colleagues as suppressors, perpetrators of discrimination, disrespectful and racist in the working environment. They did not give the 
participants support, acknowledgment and attention. The participants were in turn, constructing themselves as disempowered by both junior and senior colleagues, as they were depriving them of their authority and their support, by making them feel unimportant and powerless.

The above extracts are in line with Subbaye and Vithal (2017) as well as Rollock (2019) who asserted that Black women academics are often forced to carry out their work activities in hostile environments as they still experience (both racial and sexist) discrimination within the academic spaces (Mohope 2014). Encounters such as having their intelligence, their qualifications, and their authority constantly called into question; being excluded from important activities and having people of other races judge them. Negative stereotypes are some of the difficulties that Black women encounter (Subbaye and Vithal 2017; Bhana and Pillay 2012). The above emphasises the importance of legitimising the counter-stories of Black women professors whose stories expose, analyse, and challenge racial privilege (Stinson 2013; Aguirre 2000).

\section{Black women professors navigating the challenges in institutions of higher education}

As alluded to above, people's ways of understanding the world are a result of the socio-cultural economic and the historical arrangements prevailing in that space and time (Burr 2006; Galbin 2014; Creswell 2009). Amid the challenges that the participants encountered in the institutions of higher education, they mentioned being vocal, being intentional about excelling in their work and adopting a transformational leadership style, so as to be instrumental in their professorial journey. Freire (1972) believed that a rational and informed understanding of history, economics, poverty, oppression and exploitation was a prerequisite for disadvantaged individuals to initiate and to establish a progressive change.

\section{Being vocal}

The literature shows that Black women can use the support that they receive in and outside of the workplace, to develop confidence to voice their opinions about issues such as discrimination and other difficult circumstances that especially affected them as Black women (Mokhele 2013). Most of the participants indicated how they used their vocalism to navigate being Black women professors in South African higher education institutions.

While talking about how she manages some of the strains she has encountered as a professor in higher education, Sbahle mentioned that:

\footnotetext{
“Well I'm very outspoken so they [colleagues] know exactly how I think ... and they have accepted
} 
that like you know, what she does have something to contribute."

Gabi similarly mentioned that:

"I have worked here for 10 years, and I have been very vocal ... so I think because of that they noticed me. I said you know what, I will take this, I will not take that."

Zinhle also stated that:

"I've learned to be able to express myself and not to be shy. Yes definitely if I've got something to say I will say it as is, without any fear or shyness at all and maybe that helps me in that nobody can ride over me. No! no! no! that will never happen so ... I'm in a position of leadership or ... authority. I'm able to just declare who I am and how I manage things so everybody knows exactly so maybe that helps in a way."

Ramohai and Marumo (2016) asserted that having a voice and an ability to drive changes in one's work environment are important aspects in leadership. Having the capacity to talk and to engage in all discussions, discourses and decisions in their work environment can also be empowering. The findings are congruent with critical conscious's critical reflection which is the process of questioning social arrangements and structures that marginalize groups of people. This includes history and thinking that perpetuates existing structures of inequalities (Christens et al. 2015).

These findings are particularly encouraging as the literature postulates that women in senior positions often report incidences of institutional practices, processes and discourses that marginalise their voices. Freire (1972) asserted that critical consciousness of inequities and their causes and insisting on transforming their social and their political circumstances places marginalised individuals in a position to resist oppression. The participants, by being vocal, were demonstrating their resistance to being marginalized, isolated, and undermined in higher education institutions.

\section{Being intentional about excelling in their work}

Most of the participants showed themselves to be intentional about excelling in their work, which was another way that they challenged difficulties such as being undermined, even as professors. Sbahle stated that:

"For you to ... succeed I guess is that you need to generate funding ... and luckily, I'm good at that. I can really raise money on my own. Yes, so I can write a proposal and get money. We don't get mentored at all ... I learned the valuable skill how to do things on my own so that helped ... it [the discrimination] pushes me to try to prove I'm the best ... I make sure that you know should people question whether I deserve something or not, my CV speaks for itself." 
Thobile stated that:

"I learnt in the academia is that you've got to read, you've got to read your stuff, you must know your stuff. You must read policies so immediately you understand all this, you have power. Power is in the knowledge because once you possess that power, you know that if I'm saying this, I have backup, I have evidence of what I'm talking about. You are not going to argue with me and say it is this. So that has assisted me. That has assisted me a lot."

In addition to serving as institutional leaders, professors function as disciplinary leaders. Most of the participants demonstrated continuous excellence in their academic discipline by managing their independent academic pursuits well, by securing funds and showing academic insights and expertise within their specialised fields. Through excelling academically, the participants were proving that they should not be undermined and that they are capable of leading, they are knowledgeable, and they are making significant contributions. The participants were challenging and resisting the racist and the sexist culture that is prevalent in their institutions, by keeping their focus on their work and by so doing, shifting stereotypical notions of Black and women professors.

\section{Adopting a transformational leadership style}

As stated earlier, professors are also significant in that they have the responsibility of shaping and developing the next generation of academics, through career development, mentoring, and advising. Despite encountering challenges such as being unwelcomed and undermined in higher education institutions, most of the participants indicated how they were intentional about bringing about change as leaders in higher education. The participants focused on creating favourable working spaces, opportunities and mentoring their junior staff and students, as they navigated being Black women professors in South African higher education institutions. Adopting a transformational leading style challenges the racism and that patriarchy that often exists in higher education institutions. While talking about her leadership style Zinhle mentioned that:

"You know my being the current head of the department, my responsibility above everything else is to make sure that I create a conducive environment for people to thrive, everybody, level ground, no favouritism."

Sbahle also stated that:

"So now the younger Black academics I do mentor them."

Gabi said that: 
"I encourage them [Black students] and I share opportunities with them and they get these opportunities; and some of them have now become staff members here; in fact two of them have become lecturers in the same department."

Through supporting especially Black academics, the participants were portraying themselves as conscious of the oppression that Black people encounter in the academic space, in terms of support and exclusion. The participants presented themselves as intentional and proactive in presenting opportunities for more Black academics and ensuring that more of them succeed and thrive in institutions of higher education. This is supported by Christens et al. (2015) who asserted that critical consciousness makes it clear that the actions it encompasses are those specifically oriented toward changing unjust systems and policies (Christens et al. 2015). The participants in their constructions were empowering those under them, through the power that they possess as professors in institutions of higher education. Here they were justifying themselves as empowering as they were attempting to undo the systematic injustice that the institutions of higher education went through during the apartheid regime. The participants were introducing new styles of management. As stated earlier Demos et al. (2014) argued that women can be agents of change in the managerial culture, as they are in a position to challenge the masculine and the racist management forms which primarily support males and the White race. The participants were demonstrating critical action, meaning that the individual makes efforts to change the perceived unjust systems and policies (Christens et al. 2015).

\section{CONCLUSION}

This article showed how Black women professors are attached to their professorial journey and how they portray themselves is dependent on their contextual setting. Through the CRT, the composite stories of the Black women professors were legitimised. The findings showed that even though Black women professors positioned certain discursive objects as disempowering, they also portrayed others as empowering to them; and themselves as empowering to their junior colleagues.

\section{ACKNOWLEDGEMENT}

This work is based on the research supported by the National Institute for The Humanities and Social Sciences.

\section{REFERENCES}

Aguirre Jr., Adalberto. 2000. "Academic storytelling: A critical race theory story of affirmative action." Sociological Perspectives 43(2): 319-339. 
Albertus, Rene W. 2019. "Decolonisation of institutional structures in South African universities: A critical perspective." Cogent Social Sciences 5(1): 1620403.

Allison, Donnetrice, C. 2008. "Free to be me? Black professors, White institutions." Journal of Black Studies 38(4): 641-662.

Bhana, Deevia, and Venitha Pillay. 2012. "How women in higher education negotiate work and home: A study of selected women at a university in South Africa." Journal of Higher Education in Africa 10(2): 81-94.

Bezuidenhout, Adèle and Frans Cilliers. 2011. "Age, burnout, work engagement and sense of coherence in female academics at two South African universities." South African Journal of Labour Relations 35(1): 61-80.

Braun, Virginia and Victoria Clarke. 2006. Using thematic analysis in psychology." Qualitative Research in Psychology 3(2): 77-101.

Braun, Virginia and Victoria Clarke. 2012. Thematic analysis. I APA handbook of research methods in psychology, Vol 2: Research designs: Quantitative, qualitative, neuropsychological, and biological, 57-71. Washington, DC, US: American Psychological Association. Washington, DC, US: American Psychological Association.

Burr, Vivien. 2006. An introduction to social constructionism. Routledge.

Campbell, Catherine and Catherine MacPhail. 2002. "Peer education, gender and the development of critical consciousness: Participatory HIV prevention by South African youth." Social Science \& Medicine 55(2): 331-345.

Christens, Brian, D., Lawrence T. Winn, and Adrienne M. Duke. 2015. "Empowerment and critical consciousness: A conceptual cross-fertilization." Adolescent Research Review 1(1): 15-27.

Collins, Alicia, C. 2001. "Black women in the academy: An historical overview." In Sisters of the academy: Emergent black women scholars in higher education, ed. R. M. Mabokela and A. L. Green, 29-41. Virginia: Stylus Publishing.

Creswell, John, W. 2009. Research design: Qualitative, Quantitative and Mixed methods Approaches $3^{\text {rd }}$ Edition. Los Angeles: SAGE.

Divala, J. J. 2014. "Black women academics in higher education: In search of inclusive equal voice and justice: Part 2: Being and belonging in South African higher education: The voices of black women academics." South African Journal of Higher Education 28(6): 2079-2087.

DeJonckheere, Melissa and Lisa M. Vaughn. 2019. "Semi structured interviewing in primary care research: A balance of relationship and rigour." Family Medicine and Community Health 7(2).

Delgado, Richard and Jean Stefancic. (Ed.). 2000. Critical race theory: The cutting edge. Temple University Press.

Demos, Vasilikie P., Catherine White Berheide, and Marcia Texler Segal. 2014. "Gender Transformation in the Academy". Gender Transformation in the Academy: Advances in Gender Research 19: ii. Emerald Group Publishing Limited. Error! Hyperlink reference not valid.https://doi.org/10.1108/S1529-212620140000019029.

Department of Higher Education and Training. 2018. Statistics on Post-School Education and Training in South Africa: 2016. Pretoria: Department of Higher Education and Training.

DHET see Department of Higher Education and Training.

Dlamini, Eunice Tressa and Jabulile Dorothy Adams. 2014. "Patriarchy: A case of women in institutions of higher education." Perspectives in Education 32(4): 121-133.

Evans, Linda. 2015. "A changing role for university professors? Professorial academic leadership as it is perceived by 'the led'." British Educational Research Journal 41(4): 666-685.

Freire, Paulo. 1972. Pedagogy of the Oppressed. Translated by Myra Bergman Ramos. New York: Herder.

Galbin, Alexandra. 2014. "An introduction to social constructionism." Social Research Reports (26): 
82-92.

Harris, Cheryl, I. 1993. "Whiteness as Property, 106 Harv.” L. rev: 1707-1711.

Hatcher, Abigail M. 2006. "Evaluating the role of critical consciousness' in a rural South African development intervention: Implications for structural approaches to HIV prevention." $\mathrm{PhD}$ dissertation. University of Cape Town.

Hiraldo, Payne. 2010. "The role of critical race theory in higher education." The Vermont Connection 31(1): 7.

Khunou, G., E. D. Phaswana, K. Khoza-Shangase, and H. Canham. (Ed.). 2019. Black Academic Voices: The South African Experience. Cape Town: HSRC Press.

Mandleco, Barbara. 2010. "Women in Academia: What can be done to help women achieve tenure?" Forum on Public Policy Online 2010(5): 1-13

Maodzwa-Taruvinga, Mandi, and Audrey Msimanga. 2014. "Contradictory location of the black woman passport academic: Embrace, alienation and vulnerability; Part 2: Being and belonging in South African higher education: The voices of black women academics." South African Journal of Higher Education 28(6): 2052-2064.

Magee, Arran and Tejendra Pherali. 2019. "Paulo Freire and critical consciousness in conflict-affected contexts." Education and Conflict Review 2(2019): 44-48.

Maphalala, Mncedisi. C. and Nhlanhla Mpofu. 2017. "Are we there yet? A literature study of the challenges of women academics in institutions of higher education." Gender and Behaviour 15(2): 9216-9224.

Maseko, P. B. Neo. 2018. "Transformative praxis through critical consciousness: A conceptual exploration of a decolonial access with success agenda." Educational Research for Social Change 7(SPE): 78-90.

McCracken-Flesher, Caroline. 2010. "Promotion to full professor: Philosophy, standards, strategies, and best practices for candidates." Academic Careers in Higher Education. https://www.uwyo.edu/ acadaffairs/_files/docs/pyth_full_prof.pdf.

McGrath, Cormac, Per J. Palmgren, and Matilda Liljedahl. 2019. "Twelve tips for conducting qualitative research interviews." Medical Teacher 41(9): 1002-1006.

Merriam, Sharan B. 2009. Qualitative research: A guide to design and implementation. San Francisco, CA: Jossey-Bass.

Miroiu, Mihaela. 2003. Guidelines for promoting gender equity in higher education in Central and Eastern Europe. UNESCO.

Mohope, Sobelai Sophie. 2014. "Becoming a new kind of professional: A black woman academic caught in a transition; Part 2: Being and belonging in South African higher education: The voices of black women academics." South African Journal of Higher Education 28(6): 1986-1998.

Mokhele, Matseliso. 2013. "Reflections of Black women academics at South African Universities: A narrative case study." Mediterranean Journal of Social Sciences 4(3): 611-619.

Msimanga, Audrey. 2014. "Too late to come back? The paradox of being a 50-year-old 'early career' black female academic: Part 2: Being and belonging in South African higher education: The voices of black women academics." South African Journal of Higher Education 28(6): 2013-2026.

Mzangwa, Shadrack, T. 2018. "The Effects of Higher Education Policy on Transformation: Equity, Access and Widening Participation in Post-apartheid South Africa." Bangladesh e-Journal of Sociology 15(1): 68-85.

Naicker, Linda. 2013. "The journey of South African women academics with a particular focus on women academics in theological education." Studia Historiae Ecclesiasticae 39: 325-336.

Ndlovu, Nokulunga Sithabile. 2014. "Turning adversity into opportunity: A black woman's journey into academia: Part 2: Being and belonging in South African higher education: The voices of black women academics." South African Journal of Higher Education 28(6): 2041-2051. 
Ramohai, Juliet. 2019. "Women in senior management positions at South African universities." Gender in Management: An International Journal 34(3): 217-232. https://doi.org/10.1108/GM-10-20170138.

Ramohai, Juliet and Khomotso Marumo. 2016. "Women in senior positions in South African higher education: A reflection on voice and agency." Alternation Journal 23(1): 135-157.

Rollock, Nicola. 2019. Staying power: The career experiences and strategies of UK Black female professors report. Goldsmiths: University of London.

Schulze, Salome. 2015. "The doctoral degree and the professional academic identity development of female academics." South African Journal of Higher Education 29(4): 260-276.

Statistics South Africa. 2016. P0302: 2016 mid-year population estimates. https://www.statssa.gov.za/ publications/P0302/P03022016.pdf.

Stats SA see Statistics South Africa.

Stinson, David. W. 2013. "Negotiating the 'White male math myth': African American male students and success in school mathematics." Journal for Research in Mathematics Education 44(1): 6999.

Subbaye, Reshma. 2017. "The shrinking professoriate: Academic promotion and university teaching." South African Journal of Higher Education 31(3): 249-273.

Subbaye, Reshma, and Renuka Vithal. 2017. "Gender, teaching and academic promotions in higher education." Gender and Education 29(7): 926-951.

Tate I. V. F. William. 1997. "Chapter 4: Critical race theory and education: History, theory, and implications." Review of Research in Education 22(1): 195-247.

Taylor, Edward. 1998. "A primer on critical race theory: Who are the critical race theorists and what are they saying?" The Journal of Blacks in Higher Education 19: 122-124.

Taylor, Edward, David Gillborn, and Gloria Ladson-Billings. 2009. Foundations of critical race theory in education. New York: Routledge.

Vandeyar, Saloshna. 2010. "Shifting selves: Constructing and negotiating academic identities." South African Journal of Higher Education 24(6): 914-934.

Watts, Roderick J. and Irma Serrano-García. 2003. "The quest for a liberating community psychology: An overview." American Journal of Community Psychology 31(1-2): 73.

Yosso, Tara J. 2005. "Whose culture has capital. A critical race theory discussion of community cultural wealth." Race Ethnicity and Education 8(1): 69-91.

Zulu, Connie. 2013. "Women academics' research productivity at one university campus: An analysis of dominant discourses." South African Journal of Higher Education 27(3): 750-767. 